BARBIERI, V.H.B.; LUZ, J.M.Q.; BRITO, C.H.; DUARTE, J.M.; GOMES, L.S.; SANTANA, D.G. Produtividade e rendimento industrial de híbridos de milho doce em função de espaçamentos e populações de plantas. Horticultura Brasileira, Brasília, v.23, n.3, p.826-830, jul-set 2005.

\title{
Produtividade e rendimento industrial de híbridos de milho doce em função de espaçamentos e populações de plantas ${ }^{1}$
}

\author{
Vitor Hugo B. Barbieri²; José Magno Q. Luz³ Césio Humberto de Brito³ Jair M. Duarte²; Luiz S. Go- \\ mes $^{2}$; Denise G. Santana ${ }^{3}$ \\ ${ }^{2}$ Syngenta Seeds, Rod. BR 452, km 142, 38405-232 Uberlândia-MG; E-mail: vitor.barbieri@ syngenta.com; ${ }^{3}$ UFU-ICIAG, C. Postal: 593, \\ 38400-902, Uberlândia-MG. ${ }^{1}$ Parte da dissertação de mestrado apresentada pelo primeiro autor.
}

\section{RESUMO}

Avaliou-se o comportamento de dois híbridos de milho doce submetidos a espaçamentos e populações de plantas. Empregou-se o delineamento experimental de blocos casualizados, em esquema fatorial 2x4x5, correspondente a híbridos (MD2001 e MD2002), espaçamentos entre linhas $(60 ; 70 ; 80$ e $90 \mathrm{~cm})$ e população de plantas $(50 ; 55 ; 60$; 65 e 70 mil plantas ha-1) com quatro repetições. Visando a obtenção de espigas com comprimento mínimo de $150 \mathrm{~mm}$, o espaçamento e a população de plantas mais adequados foram, 60 $\mathrm{cm}$ e 67 mil plantas ha ${ }^{-1}$, respectivamente. Nestas condições de manejo, o híbrido MD2001 apresentou maior produtividade de espigas e grãos, enquanto que o híbrido MD2002 apresentou melhor rendimento industrial. O comprimento e diâmetro das espigas e número de fileiras de grãos apresentaram-se como os principais componentes da produtividade de espigas e grãos, enquanto que a profundidade de grãos apresentou-se como o principal componente do rendimento industrial.

Palavras-chave: Zea mays L., comprimento de espiga, diâmetro de espiga, profundidade de grãos.

\section{ABSTRACT}

Sweet corn hybrids productivity and industrial yield as a function of spacing and plant population

In the present study we analyzed two sweet corn hybrids, in four row spacing and five plant populations. A randomized block design was used, in a $2 \times 4 \times 5$ factorial, corresponding to hybrid (MD2001 and MD2002), row spacing $(60 ; 70 ; 80$ and $90 \mathrm{~cm}$ ) and plant populations $\left(50 ; 55 ; 60 ; 65\right.$ and 70 thousand plants ha $\left.{ }^{-1}\right)$ with four replications. Aiming to obtain a minimum ear length of $150 \mathrm{~mm}$, recommended row spacing and population were $60 \mathrm{~cm}$ and 67 thousand plants $\mathrm{ha}^{-1}$, respectively. Under these management conditions, hybrid MD2001 presented greater ear kernel productivity, while hybrid MD2002 presented better industrial yield. Ear length and diameter, and the number of kernel lines represented the major components in ear and kernel productivity. Kernel depth was the major component for improving the industrial yield.

Keywords: Zea mays L., ear length, ear diameter, kernel depth.

(Recebido para publicação em 1 de dezembro de 2004 e aceito em 13 de maio de 2005)

$\mathrm{O}$ milho doce é uma das mais populares hortaliças nos Estados Unidos e Canadá. Atualmente, a área mundial cultivada é de 900 mil hectares. No Brasil cultivam-se 36 mil hectares, onde praticamente $100 \%$ da produção é destinada ao processamento industrial (SYNGENTA SEEDS, 2004). Este seguimento tem crescido nos últimos anos e a tendência é a manutenção deste crescimento, visando principalmente o mercado para exportação.

Segundo Gama et al. (1992), um dos fatores que não permitiu difundir mais rapidamente o consumo do milho doce entre os consumidores brasileiros foi a inexistência de cultivares adaptadas às nossas condições ambientais. Atualmente, devido ao crescente interesse por este mercado, algumas empresas do setor sementeiro mantêm programas de melhoramento genético, resultando em maior número de híbridos comerciais. Desta maneira, torna-se fundamental estudar práticas de manejo mais adequadas para estes híbridos.
A principal diferença entre o milho doce e o milho convencional é a presença de alelos mutantes que bloqueiam a conversão de açúcares em amido, no endosperma, conferindo o caráter doce. Vários alelos foram identificados e atualmente são utilizados comercialmente. Todos eles são caracterizados por promoverem alterações na composição dos carboidratos no endosperma, mas diferenciam-se quanto à proporção de amido e açúcar no grão, e em relação à posição nos cromossomos em que estes alelos estão localizados (TRACY, 2001).

Muitos são os fatores envolvidos na obtenção de alta produtividade, dentre eles estão o híbrido a ser utilizado, o espaçamento entre linhas e a população de plantas. Apesar de o agricultor estar sempre buscando ajustar os fatores de produção com o objetivo de produzir cada vez mais, na atividade agroindustrial é importante também considerar as necessidades do processamento na fábrica. Altas produtividades não necessariamente resultam em espigas adequadas para a indústria. Características como comprimento e diâmetro da espiga e profundidade e largura de grãos são essenciais no desempenho industrial. De acordo com Paiva Júnior (1999), a preferência por espigas maiores deve-se à maior eficiência das máquinas desgranadoras.

A utilização de diferentes espaçamentos entre linhas e população de plantas, buscando a melhor distribuição espacial, são recursos eficientes para extrair o máximo de potencial produtivo do híbrido. Por outro lado, quando se trabalha com milho doce, é primordial considerar os efeitos desta prática nas características do processamento industrial, como por exemplo, diâmetro e comprimento da espiga, profundidade e largura de grãos.

Devido às poucas informações relacionadas a espaçamento entre linhas e densidade de plantas, específicas para o milho doce e que contemplem as necessidades industriais, muitas lavouras têm sido implantadas sob espaçamentos 
maiores e densidades baixas. Corrêa (1992) recomenda espaçamento de 90 a $100 \mathrm{~cm}$ entre fileiras e de 20 a $30 \mathrm{~cm}$ entre plantas, obtendo-se uma população aproximada de 40 a 50 mil plantas ha-1.

Muitos trabalhos demonstram que o melhor arranjo espacial das plantas de milho contribui para incrementos no rendimento de grãos. Dados de dez anos de cultivo de milho nos Estados Unidos demonstraram aumento médio de produtividade de $340 \mathrm{~kg} \mathrm{ha}^{-1}$, quando se reduziu o espaçamento de $76 \mathrm{~cm}$ para $50 \mathrm{~cm}$ (OHIO, 2003 citado por PALHARES, 2003). Argenta et al. (2001), ao investigarem o efeito da redução do espaçamento entre linhas sobre o rendimento de grãos, concluíram que a resposta do rendimento de grãos de milho à redução do espaçamento entre linhas é influenciada pelo híbrido e pela densidade das plantas. Bortoline (2002), estudando a melhor distribuição de espaço entre plantas, com a redução do espaçamento entre linhas, obteve aumento no rendimento de grãos da cultura.

Em adição ao espaçamento entre linhas, a população de plantas também constitui um dos fatores fundamentais para se obter altos rendimentos, devido ao melhor aproveitamento dos diversos fatores ambientais (nutrientes, umidade e luz). Deve ser levado em consideração que a densidade ótima depende das características agronômicas de cada cultivar. Pequenas alterações na densidade de plantio implicam em modificações no rendimento de grãos (DOURADO NETO, et al., 2001; MUNDSTOCK, 1977). Incrementos na produtividade de espigas e grãos e no rendimento industrial têm sido atribuídos a determinadas características da espiga, onde o real conhecimento destas correlações, somado a informação do efeito da distribuição espacial, torna-se imprescindível na busca por melhores resultados.

O presente trabalho teve como objetivo determinar o comportamento de dois híbridos de milho doce em diferentes espaçamentos entre linhas e populações de plantas quanto à produtividade e rendimento industrial.

\section{MATERIAL E MÉTODOS}

O experimento foi realizado na Est. Exp. de pesquisa da Syngenta Seeds Ltda, no município de Uberlândia-MG, situada à latitude de $18^{\circ} 91^{\prime} 86^{\prime \prime}$ Sul, logitude $48^{\circ} 17^{\prime} 19^{\prime \prime}$ 'Oeste e altitude de $925 \mathrm{~m}$, entre 28/10/2003 e 10/02/2004.

Os híbridos de milho doce avaliados foram um simples MD2001 e um triplo MD2002, ambos superdoce, contendo o alelo shrunken2 (sh2). A semeadura foi realizada manualmente, com $20 \%$ a mais de sementes, relativo a cada população por linha de plantio. Desbastou-se aos 25 dias após a emergência, ajustando o número de plantas de acordo com o estande desejado para cada espaçamento entre linhas.

O delineamento experimental foi de blocos casualizados, em esquema fatorial $2 \times 4 \times 5$, correspondente a híbridos (MD2001 e MD2002), espaçamento entre linhas $(60 ; 70 ; 80$ e $90 \mathrm{~cm})$ e densidade de plantas $(50 ; 55 ; 60 ; 65$ e 70 mil plantas $\mathrm{ha}^{-1}$ ), respectivamente, totalizando 40 tratamentos, com quatro repetições. A parcela experimental foi de quatro linhas de quatro metros de comprimento, sendo considerada como área útil as duas linhas centrais.

De acordo com os resultados da análise química do solo, perfil de 0 a 20 $\mathrm{cm}, 2,75 \mathrm{dag} \mathrm{kg}^{-1}$ de matéria orgânica, $32,9 \mathrm{mg} \mathrm{dm}^{-3}$ de fósforo, $76,9 \mathrm{mg} \mathrm{dm}^{-3}$ de potássio, $\mathrm{pH}$ igual a 5,95 e seguindo as recomendações de Ribeiro et al. (1999), efetuou-se a adubação de plantio com o formulado 08-20-20, na dose de $600 \mathrm{~kg} \mathrm{ha}^{-1}$, e duas coberturas com 20-00-20 (250 $\left.\mathrm{kg} \mathrm{ha}^{-1}\right)$ aos 20 e 35 dias após a emergência.

Foram efetuadas pulverizações com inseticidas e herbicidas indicados para a cultura controlando as pragas e plantas daninhas incidentes, nas doses recomendadas pelos fabricantes.

A colheita das espigas foi realizada quando os grãos apresentavam $73 \%$ de umidade, colhendo-se todas as espigas da parcela útil manualmente. A umidade dos grãos foi determinada utilizando um destilador, onde a água extraída de 100 gramas de grãos foi considerada como sendo a porcentagem de umidade contida nos mesmos.

Mensurou-se a quantidade de graus dia $^{-1}$ que cada híbrido acumulou da semeadura a colheita. O híbrido MD2002, por exigir uma maior quantidade de graus $\mathrm{dia}^{-1}$ para atingir o ponto de colheita, foi colhido três dias após o MD2001.

Foram avaliados: produtividade de espigas (pesagem de todas as espigas com palha, em $\mathrm{t} \mathrm{ha}^{-1}$ ), produtividade de grãos (os grãos de todas as espigas foram cortados rente ao sabugo com auxílio de uma faca e pesados em uma balança de precisão, em t ha ${ }^{-1}$ ), rendimento industrial (obtido da divisão do peso de grãos pelo peso de espigas com palha, em porcentagem), número de fileiras de grãos por espiga (obtido contando-se o número de fileiras em uma amostra correspondente a dez espigas da parcela útil), comprimento das espigas em $\mathrm{mm}$ (da base ao ápice da espiga, em uma amostra de dez espigas da parcela útil), diâmetro das espigas em mm (obtido no meio da espiga, com auxílio de um paquímetro digital, em uma amostra de dez espigas da parcela útil), profundidade e largura de grãos (partiramse as espigas manualmente, e com auxilio do paquímetro digital, mediramse, em milímetros, quatro grãos em lados opostos e cruzados no meio da espiga, de 10 espigas da parcela útil) e espigas descartadas por podridão de grãos (relação entre o número de espigas podres em relação ao total de espigas da parcela útil, em porcentagem, sendo que todas as espigas que apresentaram pelo menos um grão com sintomas foram consideradas podres).

Os dados foram testados quanto às pressuposições da análise de variância para averiguar a existência de normalidade dos resíduos (teste de ShapiroWilk) e homogeneidade das variâncias (teste de Bartlett). As características produtividade, número de fileira e profundidade de grãos foram transformadas para $(x+0.5)^{1 / 2}$, enquanto que rendimento industrial e porcentagem de espigas descartadas por podridão de grãos foram transformadas para arc sen $(x+100)$. As demais características não foram transformadas, pois apresentaram normalidade e homogeneidade das variâncias. Realizou-se a análise da variância, pelo teste $\mathrm{F}$ e as médias do fator qualitativo (híbrido) foram comparadas pelo teste de Tukey, enquanto que para os fatores quantitativos (espaçamento entre linhas e população de plantas) foram feitas regressões polinomiais, com auxílio do programa Sanest. Também, calcularam-se os coeficientes de correlações simples de Pearson, a $5 \%$ de probabilidade, para todas as variáveis estudadas, sendo a significância verificada pelo teste de $\mathrm{t}$ (ZONTA; MACHADO, 1992). 
Tabela 1. Rendimento industrial (\%) de híbridos de milho doce em função da população de plantas e espaçamento entre linhas (cm). Uberlândia, Syngenta Seeds, 2003.

\begin{tabular}{lccccc}
\hline \multirow{2}{*}{ Híbrido } & \multicolumn{5}{c}{ População de plantas } \\
\cline { 2 - 6 } & $\mathbf{5 0 . 0 0 0}$ & $\mathbf{5 5 . 0 0 0}$ & $\mathbf{6 0 . 0 0 0}$ & $\mathbf{6 5 . 0 0 0}$ & $\mathbf{7 0 . 0 0 0}$ \\
\hline MD2001 & 43,62 & 46,22 & 43,60 & 44,54 & 43,67 \\
MD2002 & 47,35 & 48,58 & 48,01 & 49,12 & 48,19 \\
\hline \multicolumn{5}{c}{ Espaçamento entre linhas } \\
\cline { 2 - 6 } & $\mathbf{6 0}$ & $\mathbf{7 0}$ & $\mathbf{8 0}$ & $\mathbf{9 0}$ \\
\hline MD2001 & 44,98 & 44,37 & 43,78 & 44,20 \\
MD2002 & 48,26 & 47,65 & 49,01 & 48,08 \\
\hline
\end{tabular}

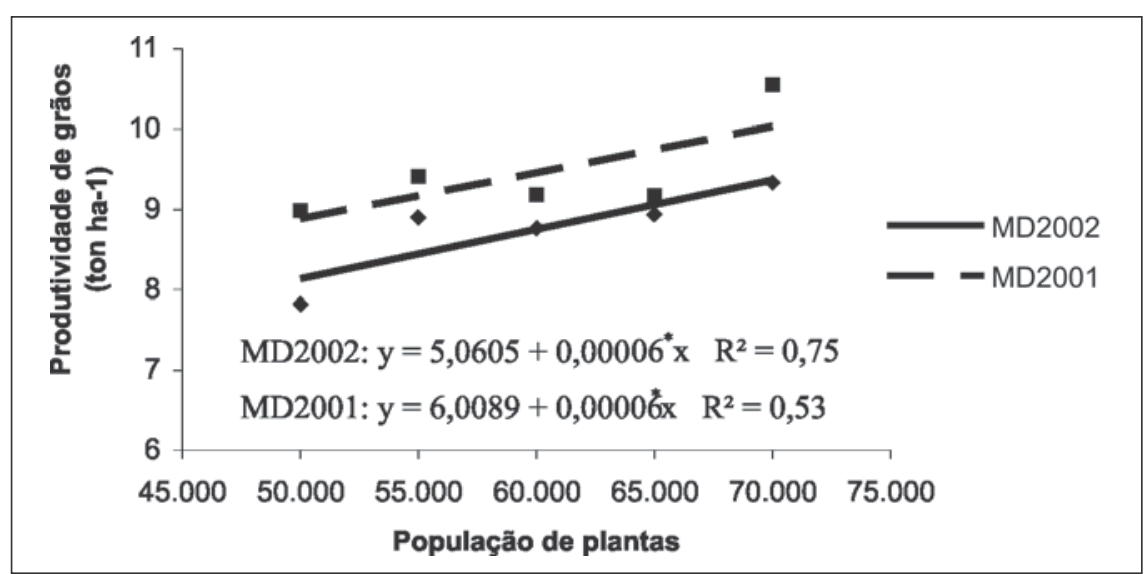

Figura 1. Produtividade média de grãos do híbrido MD2002 e MD2001 com 60 e 70 cm de espaçamento entre linhas, respectivamente, em função de populações de plantas. Uberlândia, Syngenta Seeds, 2003.

\section{RESULTADOS E DISCUSSÃO}

O híbrido simples MD2001 apresentou produtividade de espigas $\left(20,81 \mathrm{tha}^{-1}\right)$ superior ao híbrido triplo MD2002 (17,55 $\left.\mathrm{t} \mathrm{ha}^{-1}\right)$. Em boas condições ambientais, os híbridos simples podem apresentar maior potencial produtivo que os híbridos duplos, triplos e variedades, resultado de seu maior potencial genético (BELASQUE JÚNIOR et al., 2000). O cultivo em áreas de elevado nível tecnológico, característico da produção destinada a indústrias de processamento, possibilita a utilização de híbridos simples com alta responsividade produtiva.

A produtividade de espigas (PE) diminuiu linearmente quando se elevou o espaçamento entre linhas (E), independentemente do híbrido e da população utilizada. A cada centímetro aumentado no espaçamento entre linhas, espera-se uma redução de $52,30 \mathrm{~kg} \mathrm{ha}^{-1}$ na produtividade de espigas, de acordo com a equação de regressão $\mathrm{PE}=23,10-0,0523^{* *} \mathrm{E}, \mathrm{R}^{2}=$ 0,92. Fancelli e Dourado Neto (2001) verificaram que com a mudança de $90 \mathrm{~cm}$ para $70 \mathrm{~cm}$ entre linhas, obtiveram-se ganhos médios de produtividade de 8 a $12 \%$. A melhor distribuição espacial das plantas com a conseqüente redução na competição intra-específica por água e nutrientes é obtida utilizando espaçamentos menores, conforme Argenta et al. (2000) e Bullock et al. (1988).

A produtividade das espigas (PE) aumentou linearmente com a elevação da população de plantas (P). A equação de regressão $\mathrm{PE}=15,48+0,00006^{* *} \mathrm{P}$, $\mathrm{R}^{2}=0,89$, demonstra que a cada aumento de uma planta na densidade, esperase um incremento de $0,06 \mathrm{~kg} \mathrm{ha}^{-1}$ na produtividade das espigas, sendo que $89 \%$ da variação da produtividade é devido à variação nas populações de plantas. Além disso, a maior população utilizada (70 mil plantas ha $\left.{ }^{-1}\right)$, não atingiu o ponto crítico, a partir do qual, a produtividade responderia negativamente ao aumento da população. Em geral, os híbridos de milho doce não apresentam plasticidade produtiva, ou seja, não compensam a produtividade, quando em menor número de plantas por área. Resultado semelhante foi obtido por
Bortolini (2002) estudando três populações de milho (50; 65 e 80 mil plantas $\mathrm{ha}^{-1}$ ), onde o maior rendimento de grãos foi observado com 80 mil plantas ha ${ }^{-1}$.

Analisando os efeitos do híbrido, espaçamento entre linhas e população de plantas na produtividade de grãos, verificou-se que no híbrido MD2002, no espaçamento de $60 \mathrm{~cm}$ entre linhas, a produtividade de grãos aumentou linearmente com o acréscimo da população de plantas em $0,06 \mathrm{~kg} \mathrm{ha}^{-1}$ a cada planta acrescida (Figura 1). Desta forma, a maior produtividade de grãos, para este híbrido, 9,26 t ha-1, foi obtida com 60 $\mathrm{cm}$ e 70 mil plantas ha ${ }^{-1}$. Este resultado demonstrou que a melhor distribuição espacial das plantas, propiciada pelo espaçamento de $60 \mathrm{~cm}$, possivelmente diminuiu a competição intra-específica, possibilitando assim um aumento na produtividade de grãos em maiores populações. Para Johnson et al. (1998), a redução no espaçamento entre linhas, promoveu uma melhor eficiência na intercepção da radiação e decréscimo na competição entre plantas por luz, água e nutrientes, em virtude da distribuição equiidistante das plantas. Outro aspecto importante é a qualidade da luz recebida pelas plantas (KASPERBAUER; KARLEN, 1994). Cruz et al. (1994) costataram o mesmo resultado, estudando o efeito dos espaçamentos entre linhas e das populações de plantas, onde a melhor produtividade de grãos foi resultante do menor espaçamento nas maiores populações.

O híbrido simples MD2001 utilizando o espaçamento entre linhas de 60; 80 e $90 \mathrm{~cm}$, nas diferentes densidades, não apresentou produtividade de grãos estatisticamente significativa. Em relação ao espaçamento de $70 \mathrm{~cm}$ entre linhas, a cada planta acrescentada, espera-se um aumento linear de $0,06 \mathrm{~kg} \mathrm{ha}^{-1}$ de grãos, sendo que a maior produtividade de grãos foi obtida utilizando-se uma população de 70 mil plantas ha ${ }^{-1}$, igual a 10,2 $\mathrm{t} \mathrm{ha}^{-1}$ (Figura 1). Argenta et al. (2001), estudando a resposta de híbridos simples de milho em função do espaçamento entre linhas, obtiveram, para o híbrido Cargil 901, a 70 cm e 65 mil plantas ha-1, uma produtividade de grãos igual a 9,26 $\mathrm{t} \mathrm{ha}^{-1}$, resultados semelhantes aos obtidos neste experimento, com a população de 70 mil plantas ha-1.

O híbrido MD2001 apresentou maior produtividade de espigas e grãos 
que o MD2002, entretanto para o rendimento industrial, o híbrido MD2002 foi superior em todas as populações e espaçamentos estudados (Tabela 1). Esta variável é um importante parâmetro de produção, fundamental na escolha do híbrido de maior rentabilidade econômica no processamento. Elevada porcentagem de rendimento de grãos no processamento, resulta em uma alta eficiência na utilização de energia elétrica, equipamentos e mão-de-obra e consequentemente, retorno financeiro. Por outro lado, elevada média de produtividade de espigas e grãos, permite a compra da matéria prima (espigas/ grãos) com menor custo, além de possibilitar o aperfeiçoamento com gastos em logística, assistência técnica e colheita, principalmente, pela redução da área cultivada.

Baseado nos melhores resultados do híbrido MD2001, quanto à produtividade de espigas e grãos, e do MD2002, para o rendimento industrial, faz-se necessária uma avaliação de viabilidade econômica, que leve em consideração os custos envolvidos no processamento industrial e na produção da matéria-prima. Apesar da rentabilidade do agricultor estar associada à obtenção de alta produtividade, deve ser considerada também, a necessidade de escolha de um produto adequado do ponto de vista industrial.

O híbrido MD2001 apresentou a menor profundidade de grãos, $10,2 \mathrm{~mm}$, o maior comprimento da espiga, 158,33 mm, número de fileiras, 15,14 e largura de grãos, $8,7 \mathrm{~mm}$, quando comparado como o híbrido MD2002, com 10,78 mm, $147,46 \mathrm{~mm}, 14,34$ e $8,45 \mathrm{~mm}$, respectivamente. $\mathrm{O}$ número de fileiras demonstrou ser uma característica determinada pelo tipo do híbrido, onde possivelmente, apresente-se como componente importante na obtenção das altas produtividades de espigas e grãos do híbrido MD2001. Resultados semelhantes foram obtidos por Vazquez e Silva (2002) onde a variação no espaçamento não provocou alterações no número de fileiras por espiga.

Notou-se um decréscimo linear de 0,6 e 0,09 mm no comprimento e diâmetro de espiga, respectivamente, a cada 1000 plantas aumentadas na população (Figura 2). Entretanto, há uma compensação na produção devido ao aumento no número de plantas por área e o consequente aumento

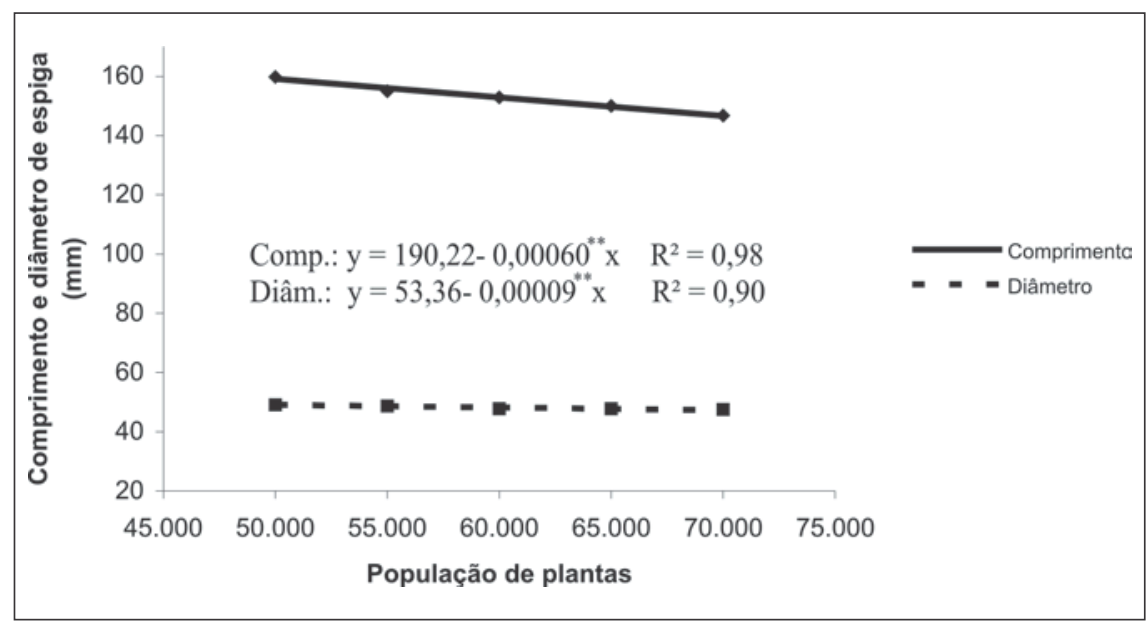

Figura 2. Comprimento e diâmetro de espiga de milho doce em função de populações de plantas. Uberlândia, Syngenta Seeds, 2003.

no número de espigas por área (Embrapa, 1996). Por outro lado, é importante adequar a performance agronômica com as necessidades do processamento industrial. Para Gama e Parentoni (1992), o processamento industrial de milho doce, em larga escala exige espigas de comprimento e diâmetro uniforme, de tal forma que facilitem o corte dos grãos pelas máquinas.

A maioria das indústrias processadoras buscam trabalhar com espigas de comprimento médio não inferior a $150 \mathrm{~mm}$. Utilizando a equação de regressão do comprimento da espiga em função da população de plantas, encontrou-se uma população máxima de 67034 plantas ha ${ }^{-1}$ para atingir este objetivo, nas condições deste experimento. Rangarajan et al. (2002), estudando o efeito de híbrido de milho doce em diferentes espaçamentos e populações de plantas sobre as características da espiga, observaram que o comprimento da espiga variou de 152 a $229 \mathrm{~mm}$, em resposta à população de plantas. No presente estudo, avaliando as diferentes populações de plantas, obteve-se um intervalo inferior a este, correspondente a 148 e $160 \mathrm{~mm}$, respectivamente, para as maiores e menores populações utilizadas (Figura 2).

Verificou-se decréscimo na profundidade e largura de grãos com o aumento da população de plantas (Figura 3). A cada 1000 plantas acrescidas, reduziuse em 0,03 e 0,02 mm, a profundidade e largura de grãos, respectivamente. A interferência negativa do adensamento populacional na profundidade de grãos indica a necessidade de se trabalhar com híbridos que apresentam grãos mais pro- fundos, com o objetivo de obter-se maior flexibilidade na definição da população de plantas necessárias à maior produtividade de espigas, sem contudo, afetar a uniformidade e eficiência de corte dos grãos pela redução da profundidade.

Houve efeito do adensamento populacional na largura de grãos, mostrando que a redução de $0,40 \mathrm{~mm}$ da menor para a maior população utilizada não foi suficiente para reduzi-la abaixo de $8 \mathrm{~mm}$, necessários para manter a qualidade visual dos grãos.

Em relação ao efeito das populações estudadas $(\mathrm{P})$ na porcentagem de espigas descartadas por podridão de grãos (EDPG), houve um acréscimo linear à medida que se aumentou a densidade, demonstrado pela equação de regressão $\mathrm{EDPG}=1,0823+0,0003^{* *} \mathrm{P}, \mathrm{R}^{2}=0,78$. A cada 1000 plantas acrescidas nesta, espera-se um aumento de $0,3 \%$ de espigas descartadas. Aumentando a população de 50 para 70 mil plantas ha-1 espera-se um aumento de $6 \%$ no total de espigas descartadas. Isto pode ser explicado pela maior dificuldade no controle da lagarta na espiga (Spodoptera frugiperda) nas maiores densidades. $\mathrm{O}$ orifício causado pela lagarta torna-se porta de entrada de patógenos, também, favorecidos por um micro-clima de maior umidade nestas condições (FERNANDES; OLIVEIRA, 2000).

A produtividade de espigas apresentou correlações positivas com número de fileira de grãos (NF), diâmetro (DE) e comprimento da espiga (CE). Os coeficientes de correlações simples de Pearson foram $0,59^{* *}, 0,62^{* *}$, e $0,35^{* *}$, respecti- 


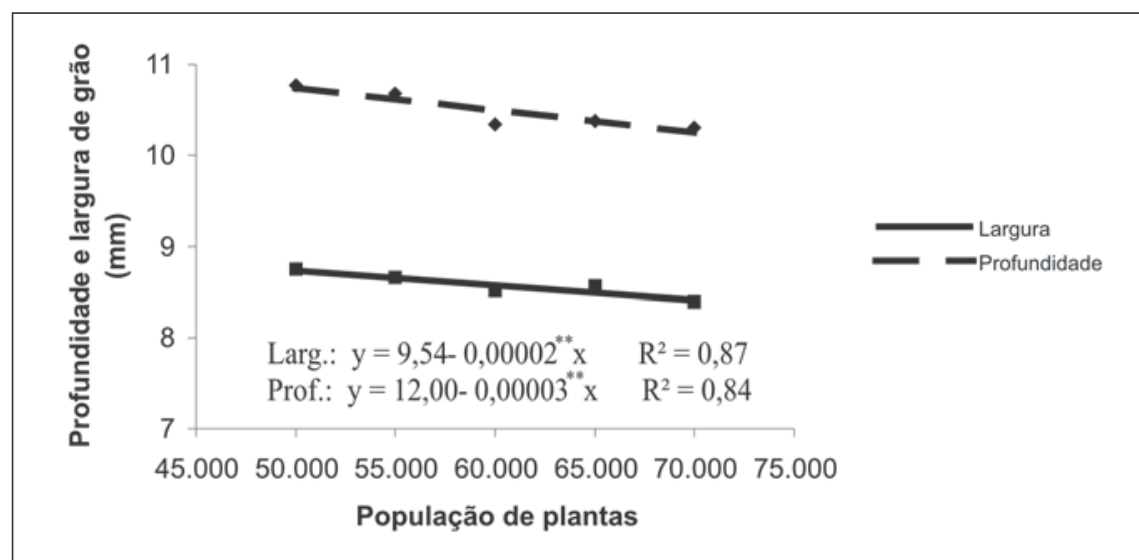

Figura 3. Profundidade e largura de grãos de milho doce em função de populações de plantas. Uberlândia, Syngenta Seeds, 2003.

vamente. Este resultado sugere que NF, $\mathrm{DE}$ e CE sejam os principais componentes da produtividade de espigas, diferindo do resultado obtido por Belasque Júnior et al. (2000) em milho comum, que não obtiveram correlação positiva entre produtividade com comprimento e diâmetro de espigas e número de grãos.

$\mathrm{O}$ rendimento industrial apresentou coeficiente de correlação simples de Pearson com a profundidade de grãos igual a $0,78^{* *}$. Este resultado coloca a profundidade de grãos como o principal componente na obtenção de elevados rendimentos industriais, sinalizando a necessidade de seleção, para esta característica, nos programas de melhoramento de milho doce. Isto pode ser explicado, uma vez que a maior profundidade promove uma uniformidade no corte dos grãos, resultando em maior aproveitamento.

A escolha do híbrido, o espaçamento entre linhas e a população de plantas, interferiram diretamente na produtividade de espigas e grãos e rendimento industrial, além do efeito nas características da espiga. Para produtividade de espigas e grãos, indica-se o híbrido MD2001 e para o rendimento industrial, o híbrido MD2002, ambos com espaçamento dentre linhas de $60 \mathrm{~cm} \mathrm{e}$ população de 67 mil plantas ha-1, objetivando obter espigas com comprimento mínimo de $150 \mathrm{~mm}$. O comprimento, diâmetro da espiga e número de fileira de grãos apresentaram-se como os principais componentes da produtividade de espigas e grãos. Enquanto a profundidade de grãos apresentou-se como o principal componente do rendi- mento industrial, constituindo-se um fator importante de seleção em programas de melhoramento de milho doce.

\section{LITERATURA CITADA}

ARGENTA, G.; SiLVA, P.R.F.; BORTOLINI, C.G.; FORNSTHOFER, E.L.; MANJABOSCO, E.A.; BEHEREGARAY NETO, V. Resposta de híbridos simples de milho à redução do espaçamento entre linhas. In: CONGRESSO NACIONAL DE MILHO E SORGO, 23., 2000, Uberlândia. Anais... Uberlândia, 2000. CD-ROM. ARGENTA, G.; SiLVA, P.R.F.; BORTOLINI, C.G.; FORNSTHOFER, E.L.; MANJABOSCO, E.A.; BEHEREGARAY NETO, V. Resposta de híbridos simples de milho à redução do espaçamento entre linhas. Pesquisa Agropecuária

BELASQUE JÚNIOR, J.; FARINELLI, R.; BORDIN, L.; PENARIOL, F.G.; FORNASIERI FILHO, D. Estudo comparativo dos componentes de rendimento e da produtividade de diferentes cultivares de milho (Zea mays L.). In: CONGRESSO NACIONAL DE MILHO E SORGO, 23., 2000, Uberlândia. Anais... Uberlândia, 2000. CD-ROM.

BORTOLINI, C.G. Influência do espaçamento entre linhas e do estande de planta de milho sobre o rendimento de grãos. In: CONGRESSO NACIONAL DE MILHO E SORGO, 24., 2002, Florianópolis. Resumos... Florianópolis, 2002. p.291.

BULLOCK, D.G.; NIELSEN, R.L.; NYQUIST, W.E. A growth analysis comparison of corn grown in conventional and equidistant plant spacing. Crop Science, Madison, v.28, n.2, p.254-258, 1988.

CORRÊA, L.A. Plantio e tratos culturais. In: EMPRESA BRASILEIRA DE PESQUISA AGROPECUÁRIA. A cultura do milho doce. Brasília, 1992. p.15-16.

CRUZ, J.C.; PACHECO, C.A.P.; FILHO, I.A.P.; OLIVEIRA, A.C. Efeito de cultivar, espaçamento e densidade de plantio sobre a produção e a qualidade de milho pipoca. In: CONGRESSO NACIONAL DE MILHO E SORGO, 20., 1994, Goiânia. Resumos... Goiânia, 1994. p.197. Brasileira, Brasília, v. 6, n.1, p.71-78, 2001.
DOURADO NETO, D.; FANCELLI, A.L.; LOPES, P.P. Milho: população e distribuição de plantas. FANCELLI, A.L.; DOURADO NETO, D. Milho: tecnologia e produtividade, Piracicaba, 2001. p.120-126.

EMBRAPA. Centro Nacional de Pesquisa de Milho e Sorgo. Recomendações técnicas para o cultivo do milho. 2.ed. Brasília: EMBRAPA-SPI, 1996. 204 p.

FANCELLI, A.L.; DOURADO NETO, D. (Coord.) Milho: tecnologia e produtividade. Piracicaba, ESALQ/USP, 2001. 261 p.

FERNANDES, F.T;; OLIVEIRA, E. Principais doenças na cultura do milho. Sete Lagoas: EMBRAPACNPMS, 2000. 80 p. (Circular técnica, 26).

GAMA, E.E.G.; PARENTONI, S.N.; REIFSCHNEIDER, F.J.B. Origem e importância do milho doce. In: EMPRESAAGROPECUÁRIA BRASILEIRA. A cultura do milho doce. Sete Lagoas, 1992. p.5-34. (Circular Técnica, 18).

GAMA, E.E.G.; PARENTONI, S.N. Melhoramento genético e cultivares de milho doce. In: EMPRESAAGROPECUÁRIA BRASILEIRA. A cultura do milho doce. Sete Lagoas, 1992. (Circular Técnica, 18).

JOHNSON, G.A.; HOVERSTAD, T.R.; GREENWALD, R.E. Integrated weed management using narrow corn row spacing, herbicides, and cultivation. Agronomy Journal, Madison, v.90, n.1, p.40-46, 1998.

KASPERBAUER, M.J.; KARLEN, D.L. Plant spacing and reflected far-red light effects on phytochrome-regulated photosynthate allocation in corn seedlings. Crop Science, Madison, v.34, n.6, p.1564-1569, 1994.

MUNDSTOCK, C.M. Densidade de semeadura de milho para o Rio Grande do Sul. Porto Alegre: UFRGS/ASCAR, 1977. 35 p. (Boletim Técnico). OHIO STATE UNIVERSITY. Corn production. (Bulletin, 472). Disponível em: <http:// www.ohioline.osu.edu/b472/front.html $>$. Acesso em: 08 jan. 2003.

PAIVA JUNIOR, M.C. Desempenho de diferentes cultivares para milho verde em diferentes épocas e densidade de semeadura. 1990. 66 f. Dissertação, (Mestrado) - Universidade Federal de Lavras, Minas Gerais.

PALHARES, M. Distribuição e população de plantas e produtividade de grãos de milho. 2003. 107 f. Dissertação, (Mestrado) - Escola Superior de Agricultura Luiz de Queiroz, Piracicaba.

RANGARAJAN, A.; INGALL, B.; ORFANEDES, M.; WOLFE, D. Row spacing and cultivar affects ear yield and quality of earlyplanted sweet corn. HortTechnology, v.2, n.3, p.410-415, 2002.

Ribeiro, A.C.; Guimarães, P.T.G.; Alvarez V.V.H. Recomendações para o uso de corretivos e fertilizantes em Minas Gerais; $5^{\circ}$ aproximação. Viçosa; CFSEMG, 1999. 359 p.

ZONTA, E.P.; MACHADO, A.A. SANEST-Sistema de análise estatística para microcomputadores. Instituto Agronômico de Campinas - SEI n 066060, 1984.

SYNGENTA SEEDS. Comunicação interna. São Paulo, 2004.

TRACY, W.F. Sweet corn. In: HALLAUER, A.R. Specialty corn. Boca Raton, 2001. p.155-198.

VAZQUEZ, G.H.; SILVA, M.R.R. Influência de espaçamento entre linhas de semeadura em híbrido simples de milho. In: CONGRESSO NACIONAL DE MILHO E SORGO, 24., 2002, Florianópolis. Resumos... Florianópolis, 2002. 289 p. 